\title{
O espírito objetivo segundo Husserl
}

\author{
Marcus Sacrini \\ Universidade de São Paulo \\ sacrini@usp.br
}

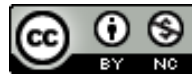

\section{Resumo}

O artigo rastreia as teses de Husserl acerca do "espírito objetivo", tomando por guia a concepção de normatividade social, de estilo linguístico, proposta por V. Descombes. Trata-se de mostrar que em suas análises de ontologia social, Husserl reconhece como base da socialidade estruturas de reciprocidade às quais os atos individuais devem se submeter. Essas estruturas operam, à sua maneira, em diferentes níveis de complexidade: relações comunicativas, relações práticas familiares e relações impessoais no interior de um povo.

Palavras-chave: Husserl, Espírito Objetivo, Socialidade, Reciprocidade

\begin{abstract}
The article follows Husserl's theses on the «objective spirit», taking as a guide the conception of social normativity (based on a linguistic model) proposed by $\mathrm{V}$. Descombes. The aim is to show that, in his analyses of social ontology, Husserl reveals as a basis of sociality the structures of reciprocity to which individual acts must be subjected. These structures function in different levels of complexity: communicative relations, practical familiar relations and impersonal relations inside a people.
\end{abstract}

Keywords: Husserl, Objective Spirit, Sociality, Reciprocity

ISSN: 0874-9493 (print) / ISSN-e: 2183-0142 (online)

DOI: 10.2478 /phainomenon-2018-0002

(C) 2018 Sacrini. This is an open access article licensed under the Creative Commons Attribution-

NonCommercial-NoDerivs License (http://creativecommons.org/licenses/by-nc-nd/3.0/). 


\section{Introdução}

A noção de «espírito objetivo» tem, sem dúvida, uma grande fortuna crítica na história da filosofia contemporânea. Consagrada por Hegel como descrição do domínio da produção espiritual que excede a vida subjetiva sem se confundir com o espírito absoluto (domínio do qual fazem parte o direito, a moralidade, a eticidade $)^{1}$, essa noção tornou-se tema de análise de uma brilhante linhagem de pensadores, das quais destacam-se as obras de G. Simmel (1900, em particular cap. 6), W. Dilthey (1910), H. Freyer (1923) e N. Hartmann (1933). É claro que inserida nas preocupações teóricas de cada um desses autores, a noção de espírito objetivo ganha diferentes nuances conceituais, de maneira que se torna mesmo difícil tratá-la como algo acabado e partilhado de modo uniforme por todos que dela se servem. Apesar das complexidades temáticas geradas pela longa exploração histórica desse tema, a qual não reconstruiremos aqui, permanece ao menos o sentido geral de que aquilo que se pode reconhecer como a espiritualidade humana não se identifica à subjetividade individual mas envolve um grau próprio de objetivação, o qual justamente cabe descrever em suas principais formas e características.

Essa perspectiva teórica foi retomada e desenvolvida em um período mais recente pelo filósofo Vincent Descombes, que em alguns artigos memoráveis da década de 90 e anos 2000, cujos temas foram desenvolvidos em seus livros do mesmo período, critica as concepções subjetivistas ou psicologizantes das relações sociais e oferece, como alternativa, uma interpretação normativa do espírito objetivo. Gostaríamos de retomar as linhas gerais dessa interpretação e, a partir dela, explicitar mais um elo na corrente de estudiosos dedicados a pensar o tema da objetividade do espírito: Edmund Husserl, autor comumente associado às análises transcendentais de inspiração cartesiana, mas que desenvolveu reflexões bastante refinadas sobre a socialidade e a objetivação das relações interpessoais. Parece-nos que o modelo normativo explorado por Descombes permite compreender de modo iluminador as posições de Husserl sobre as relações sociais, de modo a tornar visível que longe de se limitar a um

\footnotetext{
${ }^{1}$ Para uma excelente análise introdutória sobre o sentido do espírito objetivo em Hegel, $c f$. Bienenstock (2001).
} 
filósofo da subjetividade individual, o fenomenólogo também elaborou um rico pensamento acerca do caráter objetivo das relações sociais.

\section{A concepção normativa de espírito objetivo}

Em um artigo de 1995 publicado em um livro comemorativo a Charles Taylor, Descombes estabelece as linhas gerais de sua interpretação do espírito objetivo. Intitulado «Is there an objective spirit?» (Descombes, 1994), esse artigo confronta algumas maneiras tradicionais de conceber a objetividade das relações sociais (seja como a cultura material de uma sociedade seja ainda como uma espécie de sistema mental de pensamentos que opera autonomamente, conforme a antropologia estruturalista) e a elas opõe a noção de restrições normativas sobre as quais as interações interpessoais se desenrolam significativamente. Por meio dessa noção, seria possível compreender as ações coletivas e as relações sociais em geral sem reduzi-las às deliberações individuais dos sujeitos que delas tomam parte. As restrições aqui em vista não são representações mentais nem mesmo operações inconscientes, mas remetem às práticas habituais por meio das quais as interações ocorrem. Segundo Descombes, para que as interações simples do dia-a-dia social sejam bem sucedidas, pressupõem-se certas significações comuns sobre o sentido da prática em vista, as quais não precisam aparecer simultaneamente como representações na mente dos agentes, uma vez que operam como regras por meio das quais a própria interação acontece. Assim, por exemplo, em uma votação, para explorar um exemplo dado por Descombes (1994:106), deliberase sobre qual o melhor candidato, mas o sentido dessa prática social (votar) impõe uma série de restrições práticas que não estão em discussão (ter certa idade, portar um título de eleitor, dirigir-se até uma seção de votação, preencher um voto, etc.), e que justamente são condições para que a situação ocorra de forma bem sucedida. Tomar parte corretamente de uma votação depende menos de sustentar certas representações mentais do que de seguir corretamente a normatividade inerente a tal situação, que prescreve certos comportamentos específicos em detrimento de outros quaisquer.

É essa normatividade inscrita nas práticas sociais que se deve explicitar para desenvolver uma noção de espírito objetivo livre de pressupostos 
individualistas. As restrições sociais não são mera decorrência de decisões pessoais, uma vez que operam como condições de ordenação dos próprios comportamentos dos indivíduos que tomam parte em interações. Esse tema foi analisado por Descombes em um artigo de 2003, «Individuation et individualisation». Ali, entre outros tópicos tratados com finura, Descombes defende que o fato de que o indivíduo seja o agente empírico que está na base da produção social não implica que todo sentido social seja redutível ao plano individual $^{2}$. Descombes se põe, assim, frontalmente contra o postulado individualista de que toda ação social tem seu sentido derivado de uma mera somatória de atos individuais isolados. Para esclarecer essa posição, ele recorre novamente ao componente normativo constituinte das relações sociais: nossas interações supõem a correta submissão dos comportamentos individuais a certas expectativas ligadas aos papéis que cada sujeito deve exercer a fim de que a situação social se desenrole de modo mutuamente compreensivo. Mesmo tarefas sociais simples, como conversar com um desconhecido na rua, supõem uma estruturação global dos papeis individuais: quando um fala, o outro deve ouvir e em seguida responder de modo minimamente pertinente ao que foi falado, etc. Assim, a situação social não se desenrola apenas com base no ímpeto individual dos sujeitos, mas depende do exercício de papéis regrados. Inspirado pela noção wittgensteiniana de seguir regras, Descombes insiste em que não são suficientes as intenções ou representações subjetivas para garantir o sentido de uma prática social, mas que, para tanto, é preciso preencher corretamente as expectativas normativas que estruturam supra-individualmente a situação. Conforme o exemplo acima, não basta que os sujeitos queiram dialogar para que um diálogo mutuamente compreensível ocorra; é preciso submeter tal intenção às regras estruturantes dessa situação social (alternar os papéis de falante e ouvinte, zelar pela pertinência temática, etc.). Essas regras estruturantes não são dados puramente subjetivos, mas princípios «lógicos», por assim dizer, que tornam possível a concreção da situação social em vista.

\footnotetext{
${ }^{2}$ «Que o agente seja individual, e que sua ação tenha então o caráter de uma ação imputável a um agente individual, não nos diz se a maneira pela qual esse agente age manifesta uma regulação natural (instinto) ou uma significação social (instituição)» (Descombes, 2003: 29).
} 
Delineia-se, assim, de modo mais claro o que se entende por espírito objetivo. Para além das representações individuais, o domínio das interações sociais envolve um tipo de autonomia normativa que delimita o âmbito das ações individuais em interações sociais. As situações sociais são aquelas obviamente vividas por pessoas, entendidas como entes individuais. Isso não quer dizer, por sua vez, que as pessoas não tenham de se submeter a certas significações comuns para que exerçam corretamente os papéis constituintes das situações sociais. O espírito objetivo se deixa então entender como algo que de certo modo deriva dos indivíduos para vigorar (uma vez que deixe de haver pessoas, o sistema de regras e práticas habituais de uma sociedade desaparece), mas cujo poder normativo não depende, em grande medida, dos indivíduos. Simplesmente, para bem concretizar uma situação social, é preciso respeitar as regras que assim a constituem, regras que não se reduzem a representações ou impulsos pessoais.

Muito poderíamos avançar na exposição de Descombes sobre a especificidade normativa das relações sociais. Interessa-nos, mais do que reconstruir de modo exaustivo a posição desse autor, tomar os elementos até aqui acentuados como guia para a leitura de alguns textos de Husserl sobre a socialidade. Vale notar que o próprio Descombes se debruçou em ao menos um artigo sobre o problema da intersubjetividade e da socialidade na tradição fenomenológica (Descombes, 2001). No entanto, nesse texto seu veredito aponta para a insuficiência dos recursos conceituais dos fenomenólogos para apreender corretamente o caráter intrinsecamente normativo das relações sociais $^{3}$. De nossa parte, almejamos mostrar que a ideia de uma normatividade estruturante das relações sociais permite costurar textos aparentemente dispersos de Husserl, os quais Descombes não levou em consideração em seu artigo sobre a fenomenologia.

${ }^{3}$ «O que está em causa não é então que haja uma presença de outrem nem mesmo uma percepção de outrem. Perceber um outro, e dar conta de sua presença para meu comportamento, não é ainda realizar uma operação social. A vida social não começa então, como nas fenomenologias, com o reconhecimento de outrem (sobre o modelo de Robinson descobrindo os traços da presença de Sexta-Feira)» (Descombes, 2001: 152). 


\section{A ontologia social de Husserl}

\section{a) O social como fio condutor para a análise transcendental}

Husserl dedicou-se longamente ao desenvolvimento da fenomenologia, a qual, em sua versão transcendental, caracteriza-se como uma doutrina filosófica que busca tornar explícito o aparato subjetivo a priori responsável pela constituição do sentido dos mais diversos tipos de experiência concebíveis. A reflexão fenomenológica suspende a vigência da orientação natural do pensar, isto é, do modo ingênuo de lidar com tudo aquilo que venhamos a experimentar. Segundo esse modo ingênuo, a experiência é espontaneamente decodificada por categorias ontologizantes, de modo que aquilo que aparece é apreendido conforme o código do ser (ex.: o mundo dado perceptivelmente efetivamente é, existe como mundo real). $\mathrm{O}$ método fenomenológico exige que se suspenda a vigência do ser para tornar imediatamente acessível o aparecer fenomenal em toda sua evidência apodítica. Esse procedimento metódico, a epoché, porta de entrada para as análises constitutivas fenomenológicas, foi discutido por Husserl em muitos textos desde $1906^{4}$. Não nos interessa retomá-lo em detalhe aqui, mas sim explorar outro aspecto metodológico da fenomenologia talvez menos explícito que a epoché, mas que justamente serve de base para a aplicação frutífera dessa última. Por meio desse outro aspecto, pretendemos tornar visíveis as reflexões husserlianas sobre o «espírito objetivo». Trata-se da exploração dos fios condutores temáticos para a análise transcendental. Husserl apresenta uma reflexão sistemática sobre esse tema no parágrafo 21 das Meditações cartesianas, texto publicado originalmente em 1931, na França, por meio da tradução de E. Levinas e G. Peiffer ${ }^{5}$. Nesse parágrafo, Husserl esclarece que para a investigação fenomenológica avançar, o polo objetivo tematizado espontaneamente na orientação natural deve servir como guia para

\footnotetext{
${ }^{4}$ A primeira exposição pública do método da redução fenomenológica centrada na epoché da experiência natural foi o curso Einleitung in die Logik und Erkenntnistheorie. Vorlesungen 1906/07 (Husserl, 1985).

${ }^{5}$ Esse tema já havia sido tratado em outros textos anteriores. Cf. p. ex., Ideias para uma fenomenologia pura e uma filosofia fenomenológica I, §§ 149-152.
} 
a reflexão ${ }^{6}$. É preciso descrever esse polo (seja um objeto, uma região objetiva ou mesmo o mundo) de modo detalhado em suas características essenciais, para então paulatinamente desvelar os modos de consciência por meio dos quais é possível reconhecê-lo como tal. Assim, embora a meta da fenomenologia seja explicitar as operações intencionais subjetivas que atribuem sentido à experiência natural, é preciso salientar, de início, aquilo que aparece nessa experiência, para que, regressivamente, se passe da sua manifestação (devidamente neutralizada em sua posição de ser pela epoché) para o sistema de atos subjetivos que lhe atribui sentido de ser. A análise fenomenológica supõe, assim, todo o tempo, a correlação estrita entre o polo objetivo visado pelo sujeito e as operações subjetivas constituintes dessa visada intencional, e se serve da estrutura típica das objetidades para desvelar a atividade da subjetividade transcendental. Nas palavras de Husserl: «explicitar sistematicamente essa típica estrutural é precisamente a tarefa da teoria transcendental, a qual, quando toma como fio condutor uma generalidade objetiva, se chama teoria da constituição transcendental do objeto em geral enquanto objeto da correspondente forma ou categoria ou, no ponto supremo, da correspondente região») (Husserl, 2013: 90). A fenomenologia, enquanto teoria da constituição transcendental de sentido, busca revelar a estrutura geral da subjetividade por meio da sua correlação com diversos tipos de objetos ou regiões objetivas, que servem justamente de fios condutores para tornar visíveis, em regime de epoché, o complexo de atos subjetivos responsáveis por atribuir sentido àquele tipo objetivo em contraste com outros. Isso não significa que a fenomenologia abdique de sua pretensão universalista de clarificar as fontes constitutivas de todos os fenômenos que compõem a experiência natural. Trata-se apenas de reconhecer que a análise deve ser dividida conforme a especificidade dos diferentes tipos de objetos que lhe servem de guia ${ }^{7}$.

${ }^{6}$ «O ponto de partida é, necessariamente, o objeto de cada vez diretamente dado, a partir do qual a reflexão retrocede até o modo de consciência respectivo e até os modos de consciência potenciais, que nele estão incluídos à maneira de horizonte, e, por fim, até aqueles em que o objeto poderia estar de outro modo consciente como o mesmo, na unidade de uma vida de consciência possível « (Husserl, 2013: 88).

7 Afirma Husserl: «está aqui indicada uma tarefa colossal, que é da fenomenologia transcendental no seu todo, a tarefa de, na unidade de uma ordem sistemática e oniabrangente, elaborar, por níveis sucessivos, seguindo como fios condutores 
É a partir desse esquema metodológico que o tema da socialidade ganha relevância nas reflexões de Husserl. No parágrafo 58 de Meditações cartesianas, Husserl apenas indica a necessidade de remeter as camadas da experiência natural que envolvem socialização às fontes transcendentais constituintes de sentido. Nós veremos que em muitos manuscritos compostos a partir da década de 10, Husserl buscou delimitar de modo cuidadoso as principais caraterísticas disso que aparece como uma região material específica, o «'espírito objetivo'», expressão usada para caracterizar o «mundo humano e cultural enquanto tal» (Husserl, 2013: 173 [§ 58]). Seria a partir da exploração detalhada do domínio da socialidade que a fenomenologia transcendental disporia de um fio condutor adequado para explicitar a constituição de sentido da camada interpessoal da experiência natural. Não pretendemos aqui avaliar se essa recondução do domínio da socialidade às suas fontes transcendentais foi bem realizada, mas somente exibir de que maneira a caracterização do domínio do «espírito objetivo» por Husserl já antecipa em muito o modelo normativo das relações sociais apresentado por Descombes.

\section{b) A ideia de uma ontologia social}

Muitos são os textos em que Husserl busca oferecer uma descrição sistemática das relações sociais. Ideias II, por exemplo, é uma obra relativamente bem conhecida na qual Husserl apresenta o domínio do espírito como aquele das interações pessoais guiadas por relações de motivação (Husserl, 1952: §§ 4956). No entanto, nesse texto, os estratos internos por meio dos quais a socialidade se institui não são explorados em detalhe. Por sua vez, descrições precisas desse tópico são oferecidas em uma série de manuscritos postumamente publicados em três volumes (1973a, 1973b, 1973c) da coleção Husserliana dedicados ao tema da intersubjetividade e intitulados Zur Phänomenologie der Intersubjektivität (doravante citados como Hua XIII,

moventes o sistema de todos os objetos de consciência possível e, com isso, o sistema de suas categorias formais e materiais, todas as investigações fenomenológicas enquanto correspondentes investigações constitutivas, portanto, elaborar todas as investigações como rigorosa e sistematicamente edificadas umas sobre as outras e enlaçadas umas nas outras» (Husserl, 2013: 92 [§ 22]). 
$\mathrm{XIV}, \mathrm{XV}$ ). Na maior parte desses textos, Husserl preocupa-se em descrever as características essenciais das relações interpessoais, constituindo, assim, um fio condutor bastante específico para a passagem à problemática transcendental. Deve-se admitir, contudo, que nem sempre as análises eidética e fenomenológica estão claramente distintas como etapas independentes, mas operam por vezes de modo conjunto ${ }^{8}$. Neste texto, interessa-nos acompanhar principalmente a circunscrição das características eidéticas da «socialidade», sem atribuir destaque ao modo como os fenômenos sociais são constituídos pela consciência transcendentalmente considerada.

Em um manuscrito de 1910 intitulado «A doação de objetidades e de configurações sociais concretas, e a classificação dos conceitos que a elas se relacionam. Ontologia social e sociologia descritiva», é apresentado o programa fenomenológico de clarificação dos principais conceitos das investigações sociológicas, os quais, por sua vez, devem exprimir as características eidéticas dos «objetos sociais». Segundo Husserl, a compreensão das relações sociais «pode, se os conceitos possuem seu justo fundamento intuitivo, se as palavras estão ligadas às disposições correspondentes, levar a um aprofundamento, à possibilidade de uma compreensão interna, de uma elucidação e uma clarificação que trazem o objeto social concernido a uma doação intuitiva para mim, conforme sua essência« (Hua XIII, 99). O programa aqui anunciado foi sistematizado no parágrafo 19 do livro Ideias III, escrito pouco tempo depois desse manuscrito, e só publicado postumamente. Ali, Husserl acentua que os conceitos fundamentais das disciplinas científicas, aqueles que circunscrevem a própria região ontológica em que elas podem atuar, devem ser levados à sua origem intuitiva, para que se torne explícito o caráter fundamentado e sistemático do conhecimento científico neles baseado (Husserl, 1971, § 19). A clarificação dos conceitos fundantes das ciências sem dúvida é uma tarefa fenomenológica; entretanto, obviamente ela pressupõe que os conceitos eidéticos que descrevem as regiões objetivas estejam minimamente explicitados, o que, por sua vez, exige justamente o desenvolvimento das ontologias regionais. Cabe a uma ontologia regional expor os principais traços que demarcam uma região objetiva

\footnotetext{
${ }^{8}$ Agradeço a um revisor anônimo por me chamar a atenção para esse ponto.
} 
fenomênica, oferecendo, assim uma espécie de fundamentação para as análises empíricas daquele tipo fenomenal. No caso que nos interessa, lança-se, assim, a tarefa de estabelecer os limites eidéticos da região «espírito» ou «mundo social», construindo, dessa forma, uma ciência sociológica eidética fundante das pesquisas empíricas acerca das relações sociais, a qual servirá de guia para as reflexões transcendentais acerca da socialidade ${ }^{9}$. Esse tema é particularmente desenvolvido na subparte do manuscrito supracitado intitulada «Ontologia social, sociologia descritiva». Em um trecho marcante desse texto, Husserl afirma: «é importante investigar a priori as formações principais e os tipos principais da ideia de sociedade, uma vez que todas as reflexões gerais sobre o valor da sociedade devem ser guiadas pelo conhecimento da essência dessa última» (Hua XIII,103). Fica aqui formulado o projeto de explicitação das características eidéticas que determinam a priori aquilo que constitui as relações sociais em suas mais diversas manifestações empíricas ${ }^{10}$.

De fato, podemos acompanhar, em vários manuscritos publicados nos três volumes da Husserliana dedicados ao estudo da intersubjetividade, desenvolvimentos parciais dessa ontologia social, que almeja descrever as características eidéticas demarcadoras daquilo que é a socialidade em geral, independentemente das particularidades de suas manifestações empíricas. Seria impossível reconstruir em um artigo toda a complexidade da exposição husserliana acerca dessas características eidéticas. Interessa-nos apresentar os traços gerais das etapas de socialização, tais como concebidas pelo autor, para nos focar no problema central que aqui nos move: haveria lugar nessa ampla descrição do mundo social proposta por Husserl para uma noção de «espírito objetivo» entendido como normatividade supra-individual? Buscaremos mostrar que essa noção é central ao conceito de socialidade esboçado por Husserl. Além disso, veremos que esse conceito envolve outros aspectos constituintes, tal como o papel da vontade, o que permitirá esclarecer que

\footnotetext{
${ }^{9}$ Deve-se, dessa maneira, acentuar a diferença entre as tarefas teóricas ontológica e fenomenológica. Em sentido estrito, as análises fenomenológicas pressupõem a realização da epoché e a passagem para uma orientação anti-natural do pensar, o que não é o caso para as análises puramente ontológicas.

${ }^{10}$ Para uma exposição bem mais detalhada das pretensões e limites da ontologia social husserliana, $c f$. Miettinen (2014).
} 
Husserl não apenas antecipa os principais traços da interpretação de Descombes do espírito objetivo, mas pode mesmo contribuir de modo importante para o seu avanço.

\section{c) Os níveis básicos de socialização}

É importante ressaltar que Husserl apresenta o fenômeno da socialidade como resultado de uma estruturação ou fundação de diversos níveis de operações intencionais. As relações sociais supõem operações intencionais mais simples, sobre as quais então se erigem. Esse ponto fica claro em um manuscrito de 1932, intitulado «Fenomenologia da comunidade de comunicação» ${ }^{11}$. Afirma ali o autor:

À fundação da socialidade pertence uma atividade em várias camadas, de mim mesmo e co-presentada por outro: eu experimento a empatia e, verdadeiramente, por uma percepção estrangeira ativa e aprofundada, eu me dirijo ao outro com a intenção de motivá-lo a certos atos, de o motivar quando eu me dirijo a ele, quando ao falar com ele eu manifesto minha intenção e o motivo, em nossa situação comum, a compreender minha fala, meu voltar-se para ele (Hua XV, p.475).

Apresenta-se aqui uma narrativa sucinta sobre como a socialização se instaura. Supõe-se a relação empática direta entre sujeitos, isto é, o reconhecimento do alter ego a partir do eu, o que já configura relações intersubjetivas mínimas, limitadas à mera atestação perceptiva de outrem pelo eu. As relações empáticas básicas apenas garantem que há outro eu logo ali, mas não impõem por elas mesmas nenhuma relação social específica. A socialidade supõe uma atividade intencional superior, erigida sobre esse reconhecimento primário de que há outros sujeitos além do eu. Husserl analisa a primeira manifestação desse nível intencional superior como relação comunicativa entre os sujeitos ${ }^{12}$.

\footnotetext{
${ }^{11}$ Para uma análise detalhada desse manuscrito de Husserl, $c f$. Duportail (1999).

${ }^{12}$ Sobre o tratamento husserliano do tema da intersubjetividade, vale notar que muitos comentadores dedicaram-se no correr de décadas a explorá-lo. Para uma análise introdutória acessível e que trata a questão de modo abrangente, cf. Tryssesoone, 2006.
} 
Há certamente muitos tipos de situações comunicativas, das casuais às mais duradouras. Husserl busca descrever certo núcleo estruturante presente em todas elas, constituído por relações de reciprocidade entre os sujeitos comunicantes. Toda relação comunicativa impõe, por assim dizer, uma distribuição de tarefas, de modo que a atividade intencional de um sujeito se coordene com a de outro sujeito para que o resultado almejado (a compreensão mutuamente partilhada do tema em pauta) seja obtida. Conforme bem exprime Husserl, nas relações de comunicação «eu não apenas realizo atos e não sou entendido pelo outro como realizando atos, mas minha realização de atos motiva nele certa co-realização, atos que retomam a comunicação, que se inscrevem na visada da comunicação» (Hua XV, 476). A comunicação não se cumpre, assim, como mera somatória de atos individuais isolados; pelo contrário, cada sujeito deve coordenar seus atos com os atos alheios, respeitando parâmetros supra-individuais constituintes da situação comunicativa: um sujeito fala, e o outro escuta, em seguida, o ouvinte pode se tornar enunciador, e o primeiro sujeito, assume então o papel de ouvinte, etc. Dessa maneira, a socialidade se deixa apreender, mesmo no nível básico de conversações casuais, como uma coordenação recíproca de atos individuais, por meio da qual se preenche uma estrutura de sentido (a compreensão mútua) que não se esgota nos atos considerados isoladamente ${ }^{13}$.

Entrevê-se aqui uma normatividade não meramente intrasubjetiva, isto é, referente às condições para o exercício das capacidades individuais (o que o sujeito deve fazer para mover habilmente seu corpo, para produzir sons, etc.), mas interpessoal. A comunicação, mesmo em seus níveis mais simples, supõe que as intenções particulares de comunicar sejam regidas por regras estruturais que delimitam a inteligibilidade da situação comunicativa. Pela coordenação dos atos individuais, funda-se um sentido com validade interpessoal. Desse

Para uma exposição detalhada das conexões entre a análise fenomenológica da intersubjetividade e da comunicação, $c f$. Alves (2009).

${ }^{13}$ Alves captura de modo sucinto os pressupostos em jogo na relação comunicativa: «Trata-se sempre de fazer com que outrem nos apreenda como aquele que (lhe) declara isto ou aquilo, (lhe) pergunta qualquer coisa, (lhe) ordena esta ou aquela ação, na expectativa de que o seu reconhecimento daquilo que assim lhe é manifestado produza nele as respostas apropriadas» (Alves, 2009: 63). 
modo, a socialidade marca um nível específico das relações intersubjetivas, em que as ações individuais não são bem sucedidas apenas por seguirem seus parâmetros intrasubjetivos de realização, mas também por se submeterem a relações de reciprocidade com outros sujeitos.

Husserl é ainda mais específico sobre a instauração da socialidade com base nas relações comunicativas:

O agir eu-tu na comunidade linguageira, tornado possível na ligação atual da fala e da recepção compreensiva, o agir do nós, o agir ligado de modo concordante na unidade de um sentido final, de um sentido final 'acordado', do qual "partilha" cada eu individual agente. Constituição de um nós agente enquanto personalidade de ordem superior, enquanto unidade de uma subjetividade ativa, por assim dizer, de uma subjetividade pluricéfala (Hua XV: 478).

Salienta-se aqui que o agente produtor de sentido dos atos sociais não é o eu isolado e nem mesmo diferentes eus enquanto reconhecem isoladamente a si mesmos como sujeitos. Trata-se de um «agente plural», por assim dizer, o que se exprime pelo uso do «nós». Nas relações sociais de compreensão, o eu age em função de uma inteligibilidade construída «pluricefalamente», quer dizer, por dois ou mais indivíduos em ação coordenada. A condução bem sucedida de uma relação social de mútuo entendimento envolve uma produção intencional «coletiva», por assim dizer, a qual requer a submissão dos sujeitos individuais a regras estruturantes supra-individuais. O resultado da relação social não deriva da pura individualidade dos eus ali em interação, mas da correta submissão das capacidades individuais a parâmetros interpessoais de coordenação dos atos subjetivos.

As relações comunicativas são tomadas por Husserl como uma espécie de modelo fundante das relações sociais ${ }^{14}$. Como vimos, no diálogo, os sujeitos não agem isoladamente, mas um em relação ao outro, cumprindo tarefas específicas necessárias para compor significativamente a situação compreensiva em vista. A socialidade se marca, assim, desde as interações

${ }^{14}$ «Toda socialidade se baseia (...) na conexão atual da comunidade de comunicação, na mera comunidade do endereçar-se a e da sua recepção, ou de modo mais claro, do abordar [Ansprechen] e do ouvir» (Hua XV, 475). 
comunicativas básicas, pela reciprocidade intencional, de maneira que o sentido da situação vivida não se esgota nos atos individuais isolados mas decorre da composição regrada desses atos, que tomam parte na construção de um sentido mutuamente partilhável. A partir desse modelo basilar de interação social, a análise será expandida para outros tipos de laços sociais ${ }^{15}$.

Em diferentes textos, Husserl aponta para os limites intrínsecos às simples relações comunicativas em relação à diversidade de planos em que a socialização pode ocorrer. As relações sociais obviamente não se limitam à construção de compreensão mútua. Na verdade, a coordenação supraindividual que se revela na comunicação não é algo limitado ao entendimento linguístico, e sim uma marca da socialidade em sentido amplo. Inúmeros contextos práticos em que os sujeitos contribuem não só com diálogos mas com ações dos mais diversos tipos podem ser esclarecidos por meio dos parâmetros supra-individuais de coordenação ali em vigor. Às relações interpessoais que envolvem coordenação de diferentes tipos de capacidades intencionais, Husserl atribui o nome de «comunidade prática de vontade» (Hua XIV, p.169), no texto «Espírito comum I», de 1921, em contraste com as comunidades meramente linguísticas, em que a vontade se limita (ao menos nos casos mais simples) a entreter minimamente um diálogo acerca de um tema a ser partilhado (p. ex.: dois desconhecidos conversam sobre o clima nos poucos minutos em que convivem).

Um outro critério que deve ser levado em conta junto com esse da complexidade intencional das interações sociais para explicitar os níveis superiores de socialização é aquele da provisoriedade do laço social em questão. A comunidade linguística, no sentido das interações tendo em vista a compreensão mútua acerca de um tema, pode ocorrer mesmo de forma casual, quando, por exemplo, dois desconhecidos se reúnem por um tempo limitado e sem nenhum outro compromisso mútuo. Em um texto de 1910, intitulado «As sociedades e comunidades humanas», Husserl reconhece que «uma comunidade linguística não é uma unidade pessoal de ordem superior, tal como,

\footnotetext{
${ }^{15}$ Sobre o papel central da reciprocidade no pensamento social de Husserl, $c f$. Bianchin (2003). Por sua vez, Laurent Perreau explicita de modo convincente a importância dos trabalhos de G. Simmel para a noção husserliana de reciprocidade. $C f$. Perreau (2013), esp. Cap. 5.
} 
de certa maneira, uma associação o é» (Hua XIII, 108). Por si só, a comunidade linguística não implica laços duradouros, os quais, por sua vez, são uma das principais marcas das associações e outros tipos de instituições sociais. Muitos atos sociais específicos estão ligados à permanência de certas relações, de modo que a socialização casual dos sujeitos está longe de esgotar as estruturas constituintes do mundo social. Dessa maneira, para além das interações comunicativas em seu caráter provisório, é preciso considerar os laços sociais em graus superiores de durabilidade. No texto «Espírito Comum I», Husserl aponta com mais clareza o caminho a se investigar: «comunidade linguística, comunidade familiar, comunidade conjugal, comunidade do povo. Uma comunidade linguística não é um laço pessoal que cria um todo pessoal, mas em revanche um casamento, mesmo um casamento 'moderno', o é» (Hua XIV, 182). Husserl oferece aqui uma enumeração de tipos de comunidade a partir da comunicação, passando pela família e chegando até o povo. Em seguida, menciona que o primeiro nível dessa escala não institui verdadeiramente um todo interpessoal, mas apenas relações recíprocas mínimas. Husserl também indica que a união conjugal, que pode ser entendida como uma espécie de matriz da unidade familiar, institui já relações em um todo interpessoal. A passagem entre os níveis parece, assim, se marcar por graus de durabilidade ou permanência da relação social: a família é apresentada como o primeiro nível de associação interpessoal em que se instituem papéis duráveis, quiçá permanentes (ex.: um bebê nascido e criado em determinado núcleo familiar carrega permanentemente certos traços instaurados pelo convívio social).

Desse modo, cabe investigar os níveis superiores de socialidade enquanto se marcam não apenas por complexos de capacidades intencionais mas também por implicarem instituições duráveis, nas quais as relações interpessoais não se desenrolam casualmente, mas conforme funções ou papéis sociais estáveis. Eis o caráter específico dos níveis superiores de socialidade: as relações normativas de reciprocidade se instauram por meio de funções sociais bem marcadas, cuja complementação estrutural impõe restrições para o desenrolar das ações individuais (ex.: a função de filho remete à função de pai ou responsável e vice versa).

Husserl se esforça por descrever alguns dos traços eidéticos que demarcam a família como um tipo específico de associação social. Para além da enorme diversidade empírica dos tipos familiares, interessa acentuar certas relações 
normativas que regram o convívio familiar. Assim como a comunidade linguística exigia o cumprimento de certas expectativas acerca dos comportamentos individuais para se instaurar, do mesmo modo, as relações familiares não são, idealmente falando, caóticas, mas seguem restrições que se marcam pelas funções específicas assumidas por seus membros. Comenta Husserl que nas interações familiares há:

[S]imilaridades, relações recíprocas um com o outro nas aspirações vitais, na ação, nos efeitos conjuntos, no operar-em-relação-um-como-outro, por meio das quais o agir de um penetra no agir do outro, (...) em suma, uma unidade, um todo é constituído, construído a partir de sujeitos egóicos que se interpenetram ao se ligarem, enquanto a vida de um eu é co-vivida na vida do outro, é compartilhada com ele (Hua $\mathrm{XIV}, \mathrm{p} .179)$.

Nesse trecho, Husserl põe em ação aqueles critérios que mencionamos há pouco. Nas relações familiares, há interações duradouras e relativas a diversas capacidades intencionais (comunicativa, afetiva, prática, etc.). Institui-se um todo social na qual a individualidade de cada sujeito está intimamente ligada àquela dos outros. Os egos individuais dos membros da família não operam, enquanto tomam parte no todo familiar, de modo isolado, mas remetem constantemente uns aos outros para reconhecerem quem são e o que devem fazer. Nesse ponto, temos que atentar para a figura que a reciprocidade, enquanto instituinte da socialidade, aqui assume. A estrutura supra-individual normativa que guia a complementação dos atos individuais cristaliza-se por meio da distribuição de funções específicas, que definem os papéis a serem exercidos pelos membros da família. No seio familiar, a reciprocidade se exerce principalmente como fixação de papéis, cujo exercício exige comportamentos coordenados das partes de todos os membros do grupo. A coordenação dos papéis sociais constitui, assim, por complementação, um todo social que não se reduz às ações isoladas dos indivíduos.

Husserl não esboça uma tipologia exaustiva das funções familiares, mas aponta em várias passagens para o «ser pai», «ser mãe», «ser filho ou filha», «ser cônjuge», «ser o provedor», «ser o dependente» como exemplos de papéis que podem se complementar de diferentes maneiras (ex.: o pai também pode ser o 
provedor e o filho dependente, mas isso pode se inverter no final da vida do pai). Sem dúvida, muito mais poderia ser dito sobre o exercício concreto dos papéis sociais e a dinâmica interna de suas inter-relações. Importa acentuar somente que esses papéis se remetem intimamente, predelineando parâmetros de atividades individuais coordenadas, as quais devem ser respeitadas pelos indivíduos para que as interações decorram conforme as expectativas normativas que definem a particularidade de cada função social.

\section{d) A normatividade anônima da vida social}

Por meio da formulação de algumas das características mais gerais das relações familiares, Husserl pretende explicitar de que modo as relações sociais instituem totalidades supra-individuais relativamente estáveis a partir da coordenação de relações recíprocas determinadas conforme funções ou papéis bem marcados. Mas é claro, a menos que se considere um grupo familiar em completo isolamento, é preciso levar em conta que os membros de uma família estão inseridos em outros tipos de relações sociais com pessoas que não necessariamente são parentes. A família normalmente faz parte de um povo, e as relações sociais complexas no interior de um povo marcam, por assim dizer, o último estágio de concretização das estruturas da socialidade. É nesse ponto que poderemos ver com mais clareza que Husserl esboçou algo como o «espírito objetivo» tratado por Descombes naqueles artigos discutidos na seção anterior.

Eis como Husserl apresenta a unidade social intitulada como «povo», no texto «As sociedades e comunidades humanas»:

E em relação ao povo? Ele é unido por uma cultura comum e uma história comum. Em cada membro do povo vive uma consciência mais ou menos clara dos valores comuns, que nasceram naturalmente na vida comunitária e que por muitos membros do povo no passado foram deliberadamente exortados, fomentados. Uma comunidade popular tem uma memória comunitária, um saber de realizações comunitárias, de exigências comunitárias, de valores comunitários (Hua XIII, 108). 
A unidade popular remete não a interações diretas entre todos os membros, mas à partilha de uma base comum de crenças, valores, costumes que instituem uma identidade cultural mais ou menos estável no interior da qual se desenvolvem as famílias (com maior ou menor grau de reprodutibilidade dos modos de vida popularmente difundidos). A passagem das relações sociais familiares para as populares implica uma mudança significativa no tipo de reciprocidade que marca a socialidade. As relações sociais populares também se dão por meio de funções complementares que marcam os diferentes papéis sociais que compõem a coletividade social. No entanto, essas funções sociais não estão necessariamente ligadas a indivíduos específicos, uma vez que tendem a certa impessoalização. Comenta Husserl no texto «Ontologia social e sociologia descritiva»: «um casamento deixa de existir se um cônjuge morre, e não permanece o mesmo casamento se o outro se casa novamente. (...) A coisa é diferente quando um círculo de amigos perde um de seus membros e então inclui novos membros, e nós, nesse caso, falamos do mesmo círculo de amigos. Nós temos então uma sociedade» (Hua XIII, 101). Aponta-se aqui para uma diferença notável entre as relações sociais familiares e aquelas populares. No primeiro caso, há uma identificação entre o indivíduo e a função exercida. Uma relação conjugal supõe que aqueles indivíduos específicos $x$ e $y$ sejam cônjuges. Se um deles falece, não se pode simplesmente trocar de indivíduo para manter a relação. Nesse tipo de situação, há «relações conscientes funcionais ligadas a indivíduos determinados» (Hua XIII, 101). Mas não é assim em vários tipos de associações no interior de um povo. A associação pode ser reconhecida como a mesma apesar da mudança dos membros que exercem as funções pelas quais a associação realiza seus fins.

Talvez o exemplo mais claro dessa despersonalização de função social ocorra nas organizações designadas para governar o povo, nas diferentes formas de Estado, entendido como aparato administrativo para zelar pela coordenação legal dos indivíduos sob sua jurisdição. Afirma Husserl: «pertence à essência [do Estado], se ele deve se conservar idêntico a si mesmo em seu tempo de duração, que cada representante do 'governo', cada funcionário, ocupe uma 'posição' que deva ser ocupada. Se o funcionário morre, um outro é nomeado» (Hua XIII, 102). Sugere-se aqui que o Estado, enquanto uma forma social relativamente invariante no correr do tempo, depende do preenchimento de funções impessoalizadas, isto é, que não acabam com a morte ou 
aposentadoria de um indivíduo específico, pois continuam exercidas por outro funcionário. Assim, a associação interpessoal «Estado» possui uma estrutura funcional independente das pessoas que cumprem as suas obrigações.

Não importa aqui avançar em uma teoria específica do Estado, mas somente notar que no nível das interações pessoais no interior de um povo, há uma coordenação funcional das ações individuais que se impessoaliza, isto é, que não depende de uma ou outra pessoa singular para ser cumprida, e que vigora como uma espécie de atmosfera normativa anônima. Essa não é uma tese menor na ontologia social aqui esboçada. Vimos que a socialidade propriamente dita erigia-se em relações comunicativas diádicas nas quais se instaurava um «nós» agente. Em seguida vimos que a instauração desse «nós» de forma mais complexa e duradoura ocorria, por exemplo, na formação das unidades familiares. Agora, ao considerar as diferentes funções sociais no interior de um povo, anuncia-se a passagem do «nós» familiar para um «se» anônimo, para um agente indeterminado que se impõe ainda que não se identifique com ninguém em particular. É nesse ponto que devemos reconhecer os costumes e as regras de convivência como estruturas supra-individuais que não remetem especificamente a ninguém, mas que vigoram impessoalmente para todos os que se identificam com a unidade cultural popular em questão ${ }^{16}$. No importante texto «Comunidade e norma», de 1910, Husserl esboça os principais aspectos da vigência de uma normatividade anônima nas relações sociais no interior de um povo. Afirma ali o autor:

[E]m muitos grupos, mas não em todos, vigora uma norma comunitária (...). Em relação ao costume, isso significa 'age-se de tal maneira, deve-se fazer tal coisa'. Isso não quer dizer que todos façam assim, não quer dizer tampouco que é na maior parte do tempo assim, mas sim que deve ser assim, que assim é exigido. Quem exige isso? ' $O$ ' costume. Não se trata de uma exigência subjetiva. Não é apenas que eu sinta como 'certo' conduzirme assim e conduzir-me assim em relação a mim mesmo: trata-se de uma conduta em relação aos outros, e tal que eles têm o 'direito' de exigir de mim, que eles devam de modo justo esperar de mim, assim como eu em uma situação similar devo esperar deles (Hua XIII, p.105).

\footnotetext{
${ }^{16}$ I. Mayzaud já havia acentuado essa passagem do «nós» ao «se» na ontologia social husserliana. $C f$. Mayzaud (2010: 194-199).
} 
Como em todos os níveis de relações de socialidade, nas relações costumeiras age-se não meramente segundo impulsos individuais, mas em conformidade com uma normatividade comum, que distribui papeis sociais complementares para que a situação social em vista se efetive de modo plenamente significativo. $\mathrm{O}$ que marca as relações sociais costumeiras é justamente o seu anonimato; as exigências normativas não precisam ser remissíveis a ninguém em particular, pois trata-se somente de um «aqui se faz assim», de um «é isso o que se espera aqui», que garante o reconhecimento mútuo de uma unidade cultural maior.

Vale notar que assim como já ocorria nos níveis mais básicos, a normatividade social anônima não é absoluta. Há diferentes graus de coercitividade que não se impõem necessariamente, conforme nota Husserl na citação acima. Importa acentuar, entretanto, que é por relações de complementaridade no nível do costume que mesmo indivíduos que não se conhecem coordenam seus atos. Cada um deve ajustar seu agir individual às expectativas comportamentais regidas pelas estruturas de funções recíprocas em pauta, e não pode simplesmente criar ao seu bel prazer a significatividade das relações sociais. Há modos anônimos cristalizados de interações recíprocas que costuram uma identidade cultural entre os concidadãos. Dessa maneira, a socialidade, como forma das relações interpessoais em contextos complexos, aparece como um conjunto de exigências normativas impessoalizadas que regem interações de diferentes tipos (comunicativas, afetiva, de trabalho, religiosas, etc.). Constitui-se, assim, um tecido social amplo, isto é, um contexto de prescrição de interações esperadas para cada domínio das relações interpessoais. Os indivíduos se reconhecem mutuamente nesse contexto como exercendo as funções que aí lhes cabem (ex: vendedor ou comprador, trabalhador ou empregador, estudante ou professor, etc.), e devem agir de acordo com as expectativas lançadas por seus papéis nas relações recíprocas que exercem, caso busquem tomar parte em situações sociais que se desenrolam de modo bem sucedido, ao menos nos termos tradicionais de compreensão e cooperação. As interações pessoais no interior de um povo ocorrem então de modo estruturalmente próximo àquelas no interior das famílias: por complementação de atos individuais parciais que respondem a uma normatividade funcional supra-individual. No entanto, vale a pena enfatizar, no nível do povo a normatividade social opera anonimamente, de maneira que uma 
ação individual contribui para a manutenção de um sentido impessoal do todo social em vista. Tal como afirmou Husserl naquela longa citação acima, as normas sociais lançam expectativas de ações complementares da parte dos indivíduos envolvidos, o que sedimenta, de modo regrado, certa normalidade social, certo modo tradicional de funcionamento das interações pessoais naquele povo.

Dessa maneira, os atos sociais instituem unidades sociais amplas, que envolvem várias famílias e diferentes tipos de associações comunitárias em um todo social complexo, no qual vários tipos de funções ou papéis são exercidos (por vezes de modo simultâneo) pelas pessoas. Eis como Husserl apresenta, no mesmo parágrafo da citação anterior, o tecido social complexo derivado dessa ampla socialização: «uma unidade de exigências e contra-exigências que atravessam o todo da comunidade social, que são formadoras em primeiro lugar da comunidade, um sistema de deveres e direitos, cria a unidade por oposição à mera reunião de individuos 'em comércio' uns com os outros» (Hua XIII, 105). A sociedade entendida como um conjunto complexo de relações interpessoais não é uma mera reunião aleatória de indivíduos ou uma criação totalmente deliberada. As relações sociais são regradas, no sentido de instituírem funções ou papéis complementares que comprometem os indivíduos, em seus atos isolados, a tomarem parte, em comportamentos bem específicos, de uma totalidade intencional cujo sentido global não se encontra em nenhum dos atos individuais, mas na sua coordenação correta. Os indivíduos devem submeter as suas capacidades intencionais às restrições definidoras dos papéis ou funções sociais gerais, que regulam os atos esperados de cada sujeito em função de certos atos esperados de outros sujeitos participantes da situação.

Nesse sentido, age-se socialmente ao modelar seu comportamento individual conforme expectativas lançadas pela função social exercida no contexto em vista. E essa normatividade social não precisa operar como premissa de que os sujeitos partem voluntariamente para derivar sua ação de uma espécie de narrativa mental explícita. Sobre isso, é preciso esclarecer um elemento presente em citações anteriores de Husserl: a de que a exigência das normas do costume não é subjetiva. O que se quer dizer é que a socialidade não deriva apenas de um querer pessoal; as interações não se resolvem por decisões particulares; em suma, há um sentido normativo que não se reduz a conteúdos 
mentais explícitos dos sujeitos. O ponto aqui é que as normas do costume são muito mais princípios conforme os quais se age (ainda que não se tenha plena clareza do que está aí implicado) do que conteúdos explícitos a partir dos quais se atua. A normatividade social enforma a atuação individual nos contextos interpessoais mesmo se não é tematizada pelos sujeitos. Age-se conforme o esperado, age-se segundo restrições constituintes da função exercida. A efetividade das regras sociais não depende da conversão destas em uma representação explícita; antes, elas enformam o agir individual mesmo se não se atenta para elas. Certamente isso abre o problema fenomenológico de saber como a normatividade supra-individual é assimilada individualmente, o que levará Husserl a estudar o papel transcendental do hábito e da passividade na constituição e manutenção das relações sociais, tema que não estudaremos aqui ${ }^{17}$. Em todo caso, importa salientar que, em sentido geral, a vigência da normatividade social não decorre do assentimento subjetivo explícito. As funções sociais exigem, em sua própria estrutura, complementaridade, de maneira a lançar expectativas em relação às ações dos indivíduos em interação. Essas expectativas (quer dizer, essa exigência de que a função seja exercida de certo modo, em reciprocidade a funções complementares) derivam, por assim dizer, logicamente da própria função. Há uma objetividade lógica das normas sociais que impõe restrições a partir do próprio sentido da função em vista. (p. ex.: para exercer o papel social «comprador», supõem-se certos atos complementares da pessoa que exerce o papel de «vendedor», e vice versa; essas restrições garantem a própria intelegibilidade da relação social «venda de algo a alguém»). Em um texto de 1910, («Reflexão sobre a relação entre a segunda via, psicológica, e a terceira, das ciências do espírito»), Husserl expõe de modo claro essa eficácia objetiva da normatividade social. Afirma ali:

[O] homem não 'se' deixa 'determinar' somente por outro indivíduo humano (efetivo ou imaginado), mas também por objetidades [Objektivitäten] sociais que ele sente e apreende como objetidades [Gegenständlichkeiten] agentes, como poderes determinantes. Ele teme o 'governo' e executa as ordens, ele vê tal ou tal homem particular, o

${ }^{17}$ Sobre esse ponto, $c f$. Giovannangeli (2008). 
guarda, etc. apenas como representante do governo, ele teme a pessoa como mandatário. Ele sente assim o costume, a igreja, etc., como uma potência (Hua XIII, 95).

Esse texto deixa claro que no nível das interações complexas, mediadas por diferentes funções sociais, as pessoas se submetem aos condicionantes sociais e se relacionam com as instituições, o governo, p. ex., como algo objetivo, embora obviamente o governo só exista por meio de pessoas (os funcionários) que atuam coordenadamente segundo as regras instituídas. As relações sociais derivam da composição dos atos subjetivos individuais, mas seu resultado envolve uma objetividade própria, impõe um tipo de determinação que não é meramente uma questão de decisão individual, mas remete a restrições normativas a que os indivíduos estão submetidos. Essa talvez seja uma das características mais marcantes da socialidade em sua plena vigência nas interações no interior de um povo: os atos sociais instituem um tipo particular de objetividade, de estilo lógico-normativo, que restringe o âmbito da ação individual. A função social se impõe objetivamente, pois para ser bem cumprida limita o comportamento individual para além do arbítrio subjetivo. Esse talvez seja o principal tópico salientado por Husserl na citação acima: não é só uma pessoa que condiciona a outra diretamente (por coerção ou convencimento); a função social e o sistema de exigências e contra-exigências por ela instituídas como atos sociais plenos também regulam o comportamento subjetivo. A socialidade revela-se, então, como um complexo tecido de funções que dispõem normativamente acerca do comportamento esperado dos indivíduos, os quais devem atuar respeitando a reciprocidade constitutiva do sentido global da situação vivida socialmente. Trata-se de um sistema de funções que apesar de se sustentarem por meio da atuação subjetiva (que cumpre essas restrições) vigora com um grau de objetividade que não depende dos sujeitos ${ }^{18}$.

\footnotetext{
${ }^{18}$ Todas essas considerações permitem-nos recusar como simplista o seguinte veredito de Bruce Bégout: «A ideia de que as instituições se constituem por relação a normas gerais exteriores aos indivíduos e, por isso mesmo, aptas a instaurar a referência a um terceiro, a qual não é reconhecível pelos sujeitos como lhes pertencendo de imediato, é absolutamente estranha a Husserl» (Bégout, 2001: 49).
} 


\section{O espírito objetivo e o papel da vontade}

Completamos a exposição dos traços gerais daquilo que era indicado como «espírito objetivo» no parágrafo 58 de Meditações cartesianas. E como se vê, Husserl traça um quadro em muitos aspectos semelhantes àquilo que Descombes esboçava nos seus artigos aqui comentados. Segundo Husserl, em um certo nível as relações sociais se objetivam enquanto um sistema normativo de funções complementares que operam como princípios para a coordenação das ações individuais. Tal qual Descombes salientaria tantos anos depois, a socialidade, embora obviamente parta das ações individuais, não tem o seu sentido redutível aos gestos subjetivos isolados, pois justamente institui-se como a «atmosfera normativa» que regula os gestos individuais para que as interações ocorram de modo bem-sucedido. A socialidade remete, enfim, a um conjunto de significações comuns (no caso de Husserl, as funções sociais) capazes de ordenar os comportamentos individuais mesmo se não são tema explícito desses últimos.

Tornar claro que Husserl antecipa o modelo normativo de caracterização da socialidade desenvolvido por Descombes é, sem dúvida, um ponto interessante para a história da filosofia. No entanto, eu gostaria de acentuar que o modo como Husserl avança em suas explorações do espírito objetivo pode oferecer contribuições pertinentes para a discussão atual acerca do tema. Afinal de contas, como sugerido há pouco, para Husserl, a normatividade anônima das funcionalidades sociais compõem apenas parte do espírito objetivo ou dos padrões de socialização. E ao explorar outros componentes desse tópico, é possível destacar tópicos que auxiliam no desenvolvimento do modelo normativo proposto por Descombes.

Em sua caracterização do espírito objetivo, tomando por base o trabalho de C. Taylor, Descombes aponta para um conjunto de significações comuns cuja eficácia normativa não depende do assentimento dos indivíduos. Essas significações são distintas daquelas significações meramente partilhadas entre as pessoas, ou seja, que são tema de explícita elaboração subjetiva e difundidas 
como conteúdos relativamente bem $\operatorname{conhecidos}^{19}$. Por sua vez, Husserl considera um tipo de entrelaçamento entre esses dois tipos de significação que torna compreensíveis ao menos algumas mudanças na normatividade social anônima, como esboçaremos a seguir. Ocorre que tal como exposta até aqui, a normatividade social parece algo que se impõe como uma ordem autônoma sobre os sujeitos. Ora, sem dúvida não seria correto reduzir as regras da socialidade ao livre-arbítrio pessoal; porém, é preciso cuidado em relação ao exagero oposto: tomar as normas de socialização como uma esfera ontológica independente que regula de modo inexorável o comportamento individual, tal como leis naturais. Ainda que seja muito elucidativo apresentar as relações sociais como portadoras de um conteúdo lógico-normativo, seria preciso considerar outros componentes estruturantes das dinâmicas sociais para apreendê-las em toda a sua complexidade. Em particular, caberia investigar o papel da vontade e das decisões subjetivas em relação às instituições sociais.

A normatividade funcional anônima é certamente fundante das relações sociais ao regular a distribuição de papéis sociais a partir dos quais as ações individuais se coordenam em vista de interações bem sucedidas. Contudo, essa normatividade não é estática, mas passível de modificações ou afrouxamentos a partir de variações constantes no seu uso, as quais reconfiguram a vigência dos costumes. Além disso, sobre essa normatividade basilar anônima, outras normas podem ser voluntariamente instituídas, por meio de consensos produzidos em associações específicas, normas que podem mesmo se voltar sobre as práticas costumeiras, limitando-as ou alterando-as. Husserl insiste bastante nas possibilidades de moldar ativamente ao menos algumas formas de socialização. Em um manuscrito de 1910, «Comunidade e norma», tendo o direito como foco, o autor marca uma diferença importante no interior da normatividade social:

19 Segundo Descombes, Taylor «mostra como qualquer prática social pressupõe sentidos comuns, enquanto opostos àqueles meramente partilhados; e ele mostra que essas ideias e sentidos, que se assemelham ao 'espírito objetivo' hegeliano, são 'exprimidos' por instituições, que podem, portanto, ser elas mesmas comparadas a uma linguagem» (Descombes, 1994: 106). 
O direito não é uma formação cultural que nasce como um mero resultado do agir conjunto dos homens em comércio uns com os outros enquanto 'realização comunitária', tal como a língua, a literatura, a arte, etc., mas é um laço comunitário fixo, que cria unidade ao produzir a unidade da consciência voluntária, unidade de deveres e direitos, etc. (Hua XIII, p.106)

É verdade que nesse trecho os exemplos são usados de modo muito genérico (a literatura, a arte), o que pode fomentar confusão. Em todo caso, importa destacar que Husserl distingue dois tipos de formações culturais: aquele que resulta da ação coordenada dos indivíduos (por meio da normatividade funcional que se impessoaliza como costume) e aquele que resulta da ação coordenada guiada voluntariamente. O direito, embora em muitas circunstâncias possa ser mera expressão dos costumes e da tradição popular, aparece como uma instituição passível de aperfeiçoamento por associações reunidas sob a finalidade de formular as regras de convivência, de distinguir com clareza os deveres e as sanções por não cumpri-los, etc. Em suma, o direito aparece aqui como fruto de uma associação de pessoas que obviamente foi formada conforme a normatividade funcional que institui os papéis sociais tradicionais, mas que não limita sua vida social a essa regulação anônima, buscando conscientemente formular parâmetros justos de convivência.

Não se trata aqui de apontar para algum tipo de oposição entre esses dois tipos de formação cultural (anônima e voluntariamente instituída); há, certamente diferentes relações entre ambos. Por exemplo, normas instituídas juridicamente podem se tornar parte dos costumes anônimos, do «modo como se vive aqui». O que se trata de salientar é que as capacidades intencionais individuais, ainda que ordenadas pelas funções sociais, podem se voltar sobre algumas dessas funções e alterá-las refletidamente. Como vimos, o todo social é uma estrutura ordenada por um tipo de normatividade supra-individual; isso não impede que os indivíduos possam se coordenar (ou seja, agir conforme certos padrões normativos funcionais) para tentar direcionar esse todo social para a concretização de certos fins. Em outras palavras, que as relações sociais se ordenem conforme um sistema anônimo de restrições lógico-funcionais não implica que não se possa modificar algumas dessas restrições ou mesmo em 
parte reformar esse sistema ${ }^{20}$. De que maneira se garante a eficácia das restrições sociais voluntariamente instituídas em contraste com aquelas anonimamente vigentes é um problema complexo que exige descrições finas sobre os hábitos de socialização em diferentes contextos. Em todo caso, a admissão de que as decisões voluntárias têm seu papel na ordenação social, longe de significar uma recaída nas concepções que reduzem a socialidade a deliberações individuais, abre a problemática de uma teleologia histórica, tão presente nos últimos textos de Husserl. A socialidade se monta a partir de uma normatividade supra-individual, sem dúvida; mas isso pode, ao menos em parte, ser direcionado para a concretização de certos fins decididos comunitariamente como desejáveis ${ }^{21}$. Não discutiremos em detalhe esses casos aqui, mas vale notar que, desse modo, o espírito objetivo não se esgota na armadura normativa estruturadora das práticas sociais vigentes, e deixa espaço para que estratégias reflexivas comunitárias alimentem perspectivas de aperfeiçoamento das interações sociais. Em suma, por meio dessa noção, Husserl busca capturar a dinâmica histórica das relações sociais, na qual projetos teleológicos são lançados sem dúvida a partir da normatividade anônima, mas por vezes contra algumas das suas consequências, que violam finalidades éticas coletivamente almejadas.

\footnotetext{
${ }^{20}$ Nos artigos reunidos sob o título de Renovação, Husserl acentua o agir voluntário como capaz de romper certos padrões comportamentais simplesmente herdados e instaurar, ao menos em parte, um modo de vida refletidamente moldado. Esse é o caso, por exemplo, quando alguém decide regular sua vida conforme as exigências de uma vocação: «o eu já não vive simplesmente segundo impulsos, originais ou adquiridos, segundo inclinações habituais, e coisas semelhantes, mas volta-se antes, reflexivamente (...), para si próprio e para o seu agir, torna-se o eu que se determina e se escolhe, e, como na vida de vocação, que submete o conjunto da sua vida a uma vontade geral e refletida» (Husserl, 2014: 35).

${ }^{21}$ Sobre a possibilidade de transformação social voluntariamente guiada, comenta Husserl em um dos artigos de Renovação: «pertence também por essência a essa situação que as reflexões dos indivíduos singulares experimentem uma comunalização, que se propaguem em um 'movimento' social (...), motivem efeitos sociais de tipo peculiar e, finalmente, no caso limite ideal, uma direção da vontade para a autoformação e a reformação da comunidade enquanto comunidade ética - uma direção da vontade que seja da própria comunidade, e não uma simples soma das vontades fundantes dos indivíduos singulares» (Husserl, 2014: 59).
} 
Ao analisar o espírito objetivo em termos de uma normatividade de caráter lógico, Descombes explicitou um caminho profícuo para escapar da redução de todo sentido social aos indivíduos isolados, sem tornar, com isso, a sociedade um ente ou força autônoma. A exploração desse tema em vários manuscritos de Husserl abre, no entanto, um problema complementar, a saber, aquele do impacto do direcionamento voluntário das formas de socialização conforme projetos comunitários teleológicos. Esperamos desenvolver, em uma obra de maior fôlego, as conexões entre esses dois aspectos constituintes da socialidade.

\section{Bibliography}

Alves, P. M. S. (2009). Intersubjetividade e comunicação. Uma abordagem fenomenológica. Lisboa: CEFUL.

BEGOUT, B. (2001). «Pulsion, et socialisation. L'origine instinctive de la societé selon Fichte et Husserl». Em: Alter, 9, 27-64.

BIANCHIN, M. (2003). «Reciprocity, individuals and community. Remarks on phenomenology, social theory and politics». Em: Philosophy \& Social Criticism, 29 (6), 631-654.

BIENENSTOCK, M. (2001). «Qu'est-ce que 1'“esprit objectif' selon Hegel?». Em: Revue germanique internationale, 15, 103-126.

Descombes, V. (2003). «Individuation et individualisation». Em: Revue européene des sciences sociales, XLI(127), 17-35.

- (1994). «Is there an objective spirit?». Em: Tully, J.; Weinstock, D. (eds.). Philosophy in the age of pluralism. The philosophy of Charles Taylor in question. Cambridge: Cambridge Univ. Press, 96-118.

- (2001). «Relation intersubjective et relation sociale». Em: Benoist, J., Karsenti, B. (eds.). Phénoménologie et sociologie. Paris: PUF, 127-155.

DiltheY, W. (1910). Der Aufbau der geschichtlichen Welt in den Geisteswissenschaften. Berlin: Abhandlungen der Preußischen Akademie der Wissenschaften.

Duportail, G. F. (1999). Phénoménologie de la communication. Paris: Ellipses.

FREYER, H. (1923). Theorie des objektiven Geistes. Eine Einleitung in die Kulturphilosophie. Leipzig-Berlin: Teubner. 
GiOVANNANGELI, D. (2008). «Passivité et altérité: la lettre de Husserl à LévyBruhl». Em: Bulletin d'analyse phénoménologique, 8 (1), 519-533.

HARTMANN, N. (1933). Das Problem des geistigen Seins: Untersuchungen zur Grundlegung der Geschichtsphilosophie und der Geisteswissenschaften. Berlin: Walter de Gruyer.

HuSSERL, E. (2014). Europa: crise e renovação. Trad. de P. M. S. Alves; C. A. Morujão. Rio de Janeiro: Forense Univ.

- (2013). Meditações cartesianas e conferências de Paris. Trad. de P. M. S. Alves. Rio de Janeiro: Forense Univ.

(1985). Einleitung in die Logik und Erkenntnistheorie. Vorlesungen 1906/07. Hua XXIV. Den Haag: Martinus Nijhoff.

— (1973a). Zur Phänomenologie der Intersubjektivität. Erster Teil. 1905-1920. Hua XIII. Den Haag: Martinus Nijhoff.

— (1973b). Zur Phänomenologie der Intersubjektivität. Zweiter Teil. 1921-28. Hua XIV. Den Haag: Martinus Nijhoff.

— (1973c). Zur Phänomenologie der Intersubjektivität. Dritter Teil. 1929-35. Hua XV. Den Haag: Martinus Nijhoff.

- (1971). Ideen zur einer reinen Phänomenologie und phänomenologischen Philosophie. Drittes Buch: Die Phänomenologie und die Fundamente der Wissenschaften. Hua V. Den Haag: Martinus Nijhoff.

- (1952). Ideen zur einer reinen Phänomenologie und phänomenologischen Philosophie. Zweites Buch: Phänomenologische Untersuchungen zur Konstitution. Hua IV. Den Haag: Martinus Nijhoff.

Mayzaud, I. (2010). Personne, communauté et monade chez Husserl. Paris: L'Harmattan.

Miettinen, T. (2014). «Transcendental social ontology». Em: Heinämaa, S., Hartimo, M., Miettinen, T. (eds.). Phenomenology and the transcendental. New York: Routledge, 147-171.

PERREAU, L. (2013). Le monde social selon Husserl. New York: Springer.

Simmel, G. (1900). Philosophie des Geldes. Berlin: Duncker \& Humblot Verlag.

TrySSESOONE, J. (2006). «Les chemins de l'intersubjectivité dans la philosophie de Husserl». Em: Bulletin d'analyse phénoménologique, 2 (5), 3-76. 
MARCUS SACRINI ( $\mathrm{PhD}$ - University of São Paulo, 2009) is associate professor at the University of São Paulo, Brazil. His current research focuses on Husserl's phenomenology, particularly on the scope of phantasy. He has published three books in Portuguese. Two of them deal with Merleau-Ponty's philosophy: $O$ transcendental $e$ o existente em Merleau-Ponty and Fenomenologia e ontologia em Merleau-Ponty. The third one presents studies and exercises on argumentation: Introdução à análise argumentativa. Teoria e prática. He also published articles in several languages. 